\title{
The Effects Of Structure-Based Production Tasks On English Non-Majored Students' Attitudes And Grammatical Performance
}

\author{
Thy Quỳnh Nguyễn \\ Tôn Đức Thắng University \\ Hồ Chí Minh City, Vietnam \\ Hương Thu Nguyễn \\ Hoa Sen University \\ Ho Chi Minh City, Vietnam
}

\begin{abstract}
The main purpose of the current study was to investigate the effectiveness of the Structure-Based Production Tasks on English non-majored students' attitudes and grammatical performance. Fifty nine students of Ton Duc Thang University were conveniently selected and assigned into two groups: experimental group and control group. The experimental group was introduced with the alternative approach [Taskbased approach] while the control group learned with the traditional approach [Presentation-Practice-Production]. The collected data was analyzed to find out the differences between two groups in terms of the Discrete-point item test and the Integrative item test. A questionnaire-based survey was also employed to explore students' attitudes towards the treatment. The statistic result revealed that the experimental group did not exceed the control group although its result was slightly higher than that of the other. However, the significant difference of the experimental learners in the Integrative item post-test indicated that the Structure-Based Production Tasks were effective in grammar teaching. In addition, the experimental group had favorable attitudes towards the treatment. Briefly, the results of the study have offered foundations for intriguing implications withdrawn from the study to improve grammar teaching.
\end{abstract}

Keywords: Production tasks, Noticing, Grammatical performance, Task-based, PresentationPractice-Production

\section{Background to the problem}

\section{INTRODUCTION}

Grammar is necessary for language. It is the combination of form and meaning as learners not only need to focus on forms of the language but also the meanings the forms convey [Thornburry, 2008]. This suggests that grammar should not be ignored if we do not want to experience communication breakdown or misunderstanding. In a daily conversation between my student and I [the researcher], my student answered "I am staying here for two weeks" instead of "I have been staying here for two weeks" in response to the question "How long have you been staying here?" This instance emphasizes the importance of grammar in language teaching.

There are two popular ways of teaching English grammar: deduction and induction. Deductive approach is known as a top down process that students are first provided with rules and meaning of grammatical structures and apply those structures in controlled and free practice. Meanwhile, inductive approach is considered as a bottom up process that students discover rules through working on examples and exercises. 
Although inductive approach has been used, teacher-fronted approach and decontextualization have been taken into account. This practical reality is due to the pressure of exams on English teachers who have to prepare students for their written final exams. Consequently, students cannot use grammar accurately although they spent a lot of time studying English.

The English tenses and aspects are widely used in oral and written forms. Although tenses have been teaching for years, students have still failed to use them. For example "I doing homework", "you have sing" are such notable examples. These mistakes may be the consequences of rule-supplied approach and lack of contextualized input.

\section{The importance of the problem}

Among many grammatical linguistic features, the use of English tenses is such a complex aspect for students [Ellis, 1997a]. In fact, surveys of textbooks used in secondary, high schools and universities in Vietnam represent that there is high frequency use of tenses and aspects. Also, there is a close association between English tenses and many other grammatical structures such as reported speech, passive voice, and conditional sentences. In addition, English tenses are also used in everyday conversations, in exchanging information. While tenses play a crucial part in English, students still fail to use. Therefore, the researcher decided to conduct the current study under different setting [i.e., Ton Duc Thang University], grammatical structures [i.e., English tenses and aspects] and tests [i.e., written test] in order to reexamine the results of preceding studies and compared with that of the current research.

\section{LITERATURE REVIEW}

\section{Methodological options in grammar teaching}

There have been a large number of methodological options with respect to kinds of techniques and procedures used to teach grammar. Ellis [1997a] identifies two types of grammar teaching options: feature-focused options and focused communication options. Featured-focused options refer to "the practice of isolating linguistic features, teaching and testing learners one at a time in association with the structural syllabus" while focused communication options "'direct learners' attention to grammatical features through meaning-based activities" [Ellis, 1997a, p. 81]. Their distinction can be distinguished in terms of [1] intentional learning which involves a deliberate attempt to learn and [2] incidental learning in which there is an absence of intentionality to learn but may involve impromptu conscious attention to L2 features [Ellis, 2009]. A feature-focused option mainly focuses on intentional grammar learning while a focused communication option primarily pays attention to incidental grammar learning. With this mind, two types of task directs at incidental learning: meaning-focused tasks and meaningfocused tasks in combination with some device to focus learners' attention to particular linguistic features [Ellis, 1997a]. Although the latter does not require learners to make conscious effort to learn L2 features and may draw learners' attention to specific linguistic features, it is assumed to direct at incidental learning rather than intentional learning.

The other way of teaching grammar is using focused communication options. The Structured Based Communication Tasks [Loschky and Bley Vronman, 1990, discussed in Ellis, 1997a], which involve both production and comprehension, are such instances. These tasks not only require learners to focus on message content but also attend to particular grammatical knowledge. Three types of tasks are recognized: tasks that make the use of a grammatical structure "natural", tasks that make the performance of a task "easier" and tasks that make the use of a grammatical structure "essential". While it is simple to design reception and production tasks where using target structures makes the tasks natural and easier, it is difficult to design production tasks where the use of specific grammatical structures is "essential" [Ellis, 1997a]. For example, when students are asked to work on story-telling tasks, they may avoid 
using target structures and reformulate incorrect utterances just as the teacher requests clarification. In this study, focused communication options with the application of Structurebased Production Tasks are what the study aims at.

\section{Noticing}

The role of consciousness has been a controversial issue in cognitive science and second language learning. To throw light on this issue, Schmidt [1990] elicits the term "consciousness" based on input processing as "conscious processing is a necessary condition for one step in the language learning process and is facilitative for other aspects of learning" [p. 131]. Input processing, in this case, is defined as "a type of grammar instruction whose purpose is to affect the ways in which learners attend to input data" [VanPatten, 1996, p. 2]. It requires learners to pay attention to meaning, notice the target form and meaning it conveys in the input and finally notice the gap between what learners have known and their output.

"Noticing" refers to three different phenomena: learning without intention, learning without metalinguistic knowledge, and learning without awareness [Schmidt, 1990; 1994; 2001]. First, since not all intentions are conscious, not all learning is intentional. Second, explicit and implicit knowledge, according to Schmidt [1990], are a part of continuum rather than separate phenomena. Third, learning results from a subjective experience of noticing as learners pay attention to features in the input. Because of this, learning must be conscious since "SLA is largely driven by what learners pay attention to and notice in target input and what they understand of the significance of notice input to be" [Schmidt, 2001, p. 50].

Noticing reveals which features in the input are registered consciously and then become intake. Schmidt [2001, p. 5] notes that what we notice here are "elements of surface structure of utterances in the input, instances of language, rather than any abstract rules or principles of which such instances may be exemplars". Intake results from conscious cognitive comparison which helps learners observe features in the input and their output. Moreover, learners recognize that their current interlanguage system is insufficient to express the meanings they want to share. As Schmidt [2001] elicits that since features of L2 input are likely to be infrequent, non-salient and communicatively redundant, intentionally focused attention may be fundamental for successful language learning. In fact, "the role of attention is deemed crucial for further long-term memory storage of L2 information to take place" [Schmidt, 1990 discussed in Leow, 2007, as cited in DeKeyser, 2007, p. 22].

\section{Context}

Presentation-Practice-Production [PPP] model, which explanation follows by exercises, appeals to both teachers and learners. It represents an accuracy-to-fluency model of grammar teaching. The advantage is that it allows teachers to control the content and pace of the lesson, which may help them cope with unpredictability of classrooms. It also supplies a convenient model for any lessons to be conducted. As a result, this model creates safe learning environment. Nevertheless, PPP model receives a number of criticisms as it assumes that language is best learned through incremental step and accuracy precedes fluency [Thornburry, 2008].

An alternative model [Task-based approach] which is fluency-to-accuracy is adapted [Ellis, 2003]. Learning process starts with the meaning that learners want to convey by using their available linguistic resources. Then, explicit grammar teaching may be used to help them do better. As Thornburry [2008] points out that "Through successive stages of trial, error, and feedback, the learner's output is fine-tuned for accuracy" [p. 129]. 


\section{Grammatical performance}

Language ability, which refers to the combination between language competence [also called language knowledge] and strategic competence with a set of metacognitive strategies, provides learners with ability to create and interpret discourse, either in responding to tasks or in nontest language use [Bachman \& Palmer, 1996]. Language knowledge is specified in terms of organizational knowledge [i.e., how learners control structures to produce grammatical correct sentences] and pragmatic knowledge [i.e., how learners communicate meaning and produce appropriate utterances in different contexts]. The organizational knowledge refers to grammatical knowledge and textual knowledge. While the former refers to producing or comprehending formally accurate utterances or sentences, the latter concerns producing or comprehending texts, which are units of language - spoken or written [ibid.].

In the grammar learning process, explicit grammatical knowledge, which functions slowly, refers to conscious knowledge of grammatical forms and meanings. There are two kinds of explicit grammar instruction: explicit deductive and explicit inductive. While the former provides learners rules and asks them to apply, the latter supplies learners with examples of language form in which they have to search rules and make generalizations. Meanwhile, implicit grammatical knowledge relates to "the knowledge of a language that is typically manifest in some form of naturally occurring language behavior such as conversation" [Ellis, 2001, p. 252, as cited in Purpura, 2004, p. 42]. It is unconscious and is accessed quickly. To this end, "learners will notice target grammatical forms and identify form-meaning relationship so that the forms are recognized in the input and thus incorporated into the interlanguage" [Purpura, p. 43]

As the current study focuses on SBPTs in an attempt to teach grammar, the researcher employed [1] the Discrete-point item test and [2] the Integrative item test [Heaton, 1988 \& Brown, 2003]. The first test type is constructed on the assumption that language can be broken down into its component parts which can be tested successfully. In this study, the Discretepoint item test was described in form of multiple-choice test as a multiple-choice test is receptive or selective, the test-taker chooses a response from a set of responses rather than create a response. This technique tests "recognition knowledge" [Brown, 2003, p. 55] and "measures students' ability to recognize appropriate grammatical forms and to manipulate structures" [Heaton, 1988, p. 9]. Thus, it reflects learners' explicit knowledge. The second test type which places emphasis on communication and context is depicted in terms of the Reproduction test. Learners are required to provide words that fit into the blanks. Now that the ability to fit plausible words into blanks requires a number of abilities that lie at the heart of competence in a language [Brown, 2003], the Reproduction test reflects learners' implicit knowledge.

\section{Structure-based Production Tasks}

Structure-Based Production Tasks are broadly defined as "the incorporation of target structures in a task that leads to a 'behavior" " [Ellis, 2003, p. 153]. These tasks have the origin in the Structure-Based Communication Tasks discussed in Loschky and Bley-Vronman [1993]. Learners are engaged into tasks with the emphasis upon messages and have freedom to choose their own linguistic resources. In addition, incidental attention to form within the context of communication has not only been stressed but learners' grammar accuracy can be achieved by the knowledge-learned-through-practice automaticity as well.

Three features of the SBPTs are recognized: task naturalness, task utility, and task essentialness [Loschky and Bley-Vronman, 1993, as cited in Ellis, 2003, p. 152]. With task naturalness, the target structure may not be vital for task completion but is expected to arise 
naturally and frequently. For example, when exchanging information about departure time [Ellis, 2003], Present Simple tense may be used to say "I leave Hawaii at 4 o'clock". This example can be also performed through Future Simple tense to say "I will leave Hawaii at 4 o'clock" or "Be going to" to say "I am going to leave Hawaii at 4 o'clock". Briefly, different structures can be applied to perform a task. In the case of "task utility", although the target feature is not necessary for task completion, it is very "useful" in the way that using the target feature makes it easier to perform tasks. An example of this is the task "Spot the difference" [Ellis, 2003], which requires learners to describe the similarities and differences between two pictures. Despite having other ways to complete the task, learners have to use prepositions of place to make it easier to perform. Last but not least, "task essentialness" requires learners to use the target structure to complete tasks successfully. If learners do not use that feature, they will not achieve a satisfactory outcome.

\section{Prior Research}

\section{Studies on the impact of focused tasks on learners' grammatical performance}

Patanasorn [2012] compared the effectiveness of four different interaction tasks designed on the basis of focused tasks [i.e., SBPTs and CR Tasks]. Fifteen students in the intermediate level studying an intensive course of the English program in a regional university in the Southwest United States were offered to participate in. The assessment tools were Dictogloss tasks, written film recall tasks [SBPTs], matching tasks and editing tasks [CR tasks]. The target structures were English articles, passive voice structures and subject-verb agreement. Each task was performed in each classroom session as a grammar focus activity without informing learners of target structure. The data was audio recorded through an MP3 digital recorder. After that, the researcher transcribed some sentences of language-related episodes. Then, it was coded, categorized and analyzed. The results demonstrated that CR tasks were more effective in teaching grammatical structures compared to SBPTs. However, it was hard to generalize the results since the overall number of the participants was relatively low, inadequate in each session and their inappropriate learners' levels. The participants attended in each task once, which could have impacted on the results. In addition, tasks should require learners to reproduce language and include explicit instruction. Further studies would carefully pay attention to these aspects.

Gana et al. [2013] filled the gap of the previous study by focusing on the effects of Task-Based Language Teaching [TBLT] and English Grammar Mastery toward reading comprehension. The study was carried out in the second semester of English Education Study Program FKIP Unmas Denpas Patanar, Indonesia. The researchers used intact group random technique to select 52 subjects among 175 English majored students. The experimental group was instructed with TBLT while the comparison group was taught with the traditional approach. The instruments used to collect data were in form of grammar mastery test with 40 items and reading comprehension test with 30 items. Teaching instruments were lesson plans and handouts. The statistics of Two-Way Anova and the Tukey test revealed that the experimental group exceeded the control group in terms of reading comprehension. It was acknowledged that TBLT created opportunities for learners to share their problems with their friends since they felt comfortable in learning. Moreover, learners could brainstorm ideas, activate their previous knowledge, and have motivation to work without worrying about grammatical structures. However, this approach was quite new to learners.

Miri [2015] furthered this idea by testing the impact of different types of tasks [Structured and Unstructured] on the Production of Relative Clauses and Lexical Diversity. Thirty English majored students, who were in upper intermediate, participated in this research. Film was used as the main moderator in this study. At the beginning, a Nelson proficiency test was used 
to check homogeneity of the participants. Then, a fifty-minute cartoon film was shown to both groups. The experimental group [Unstructured] watched the film from the middle of the experiment whereas the control group [Structured] saw the film from the beginning. After that, learners were required to produce what they heard. The results showed that the control group outperformed the experimental group in producing Relative Clause. However, there was no significant difference between two groups in terms of vocabulary although the finding of the experimental group was slightly higher than that of the comparison one. The finding suggested using Task-Based approach could help learners be confident of producing the target language compared to the tradition approach. It created more opportunities for learners to engage in different activities and use the target language naturally. The shortcoming is that this study only used film as an instructional content. Hence, it raised the question of whether the same treatment including a grammar test and a questionnaire would produce the same results. These gaps would be fulfilled in the next studies.

The study of Badri et al. [2015] explored the effects of input enrichment [Focused Task] on students' grammar acquisition. The participants were 30 female teenagers of intermediate level in Safir Institute, Iran and were divided into two groups. Each group included 15 students who were randomly selected from 7 intact classes consisting of 105 students. Two assessment tools were parallel grammar tests extracted from Nelson book [as pre-test and post-test]. Each test included 50 items. The Oxford Placement test was handled to check homogeneity of students. Then, a pre-test was executed to assess students' initial knowledge. After that, the researcher carried out the treatment in two months, two days a week and seventy minutes per day. Both groups were received reading comprehension texts to summarize or write down topic sentences and supporting sentences. Next, a post-test was offered to both groups. The data collected from the pre-test and the post-test was used to calculate and analyze. The findings indicated that the experimental group surpassed the control group. The weakness was that the number of participants was rather small, so it was hard to generalize the results. Further studies would address the gap.

A study of students' grammatical achievement through focused and unfocused tasks was presented by Ahour et al. [2015]. Sixty freshman students majoring in English Translation were selected based on the Nelson grammar test and were divided into three groups. The experimental group [G1 and G2] included 40 students [2 groups] and the other 20 students were in the control group [G3]. Group 1 was given focused tasks. Group 2 was given unfocused tasks. Group 3 received the traditional instruction. After 10 sessions of the treatment, all three groups were required to perform a post-test, namely production test made by the researcher [also the teacher in charge] to see whether there was a significant improvement. The results showed that Group 1 [focused tasks] outweighed Group 2 [Unfocused tasks] and Group 3 [control group] in terms of grammatical achievement. It would be more convincing if there was a questionnaire to survey students' attitudes towards the treatment. This would call for further studies.

Sheikh et al. [2016] inspected the effects of focused tasks through input flooding on reading comprehension skill. Ninety higher intermediate students in high school in Iran were selected among 120 students on the basis of the Oxford Placement Test and were appointed to the experimental group [G1] and the control group [G2]. Before the treatment, a reading comprehension pre-test was administered to both groups. During the treatment, G1 was treated with focused tasks on the basis of TBLT while G2 was treated with unfocused tasks. There were three phases in the treatment: pre-task, task and post-task. First, before starting reading, learners were introduced the topic of the reading text, were activated their previous knowledge regarding vocabulary, structures and so on. Second, learners read the instruction, 
did silent reading, answered the questions and discussed the answers together with the teacher's ongoing feedback. Third, learners were taught reading skills explicitly, did the task for recalling information of the text in an activity in form of a multiple choice test in conjunction with group discussion and did a fill in blank activity for text summary. After 10 sessions of treatment, both groups received a post-test. The findings supported that focused tasks could influence learners' reading comprehension abilities. Indeed, using TBLT could build learner's self-confidence, self-fulfillment and create opportunities to improve learners' oral abilities. Nevertheless, it was difficult to conclude as the study was carried out in a short period of time.

In summary, those above studies have explored the impact of focused tasks on learners' grammatical achievement. These studies may provide supportive ideas [Gana et al., 2013; Badri et al., 2015; Sheikh et al., 2016] or contradictory ideas [Patanasorn, 2012; Miri, 2015]. Following this, previous studies regarding students' attitudes towards focused tasks are presented.

\section{Studies on the relationship between focused tasks and students' attitudes}

Rashtchi [2012] investigated the applicability of Task Based Language Teaching [TBLT] in the Iranian EFL setting in which English was taught as a foreign language. The participants were 146 learners from different backgrounds of English and 36 teachers in Tehran, Iran. The instrument was a 15-item questionnaire with two versions for learners and teachers. The findings indicated that both teachers and learners showed positive attitudes towards TBLT as it could promote communication through authentic exposure. In fact, it was necessary to focus on forms and explicit grammar teaching. As this study was only an investigation into teachers' and learners' attitudes towards TBLT, further research would fill in this gap with an experiment to see its effects.

Noor Abdullah Fattash [2013] surveyed teachers' perspectives on the effect of applying TaskBased Approach in Elementary Schools in Palestine. This study mainly focused on teachers' perspectives in terms of gender, type of school, years of experience and qualification of teachers. The subjects were thirty-eight EFL teachers from elementary schools in Tubas Governorate in the first semester of the academic year. The main tools were a questionnaire and interviews. Firstly, a 34-item questionnaire was given to all teachers. Then, the researcher used 6 questions and randomly interviewed 14 subjects. Each subject had freedom to answer the questions in 15 minutes. The responses presented that the teachers had positive attitudes towards the application of TBLT on teaching. They were, however, hesitant about using it as an instructional approach. Further research would call for an experiment to investigate the effectiveness of TBLT in teaching English as a foreign language.

Slightly different from previous studies, Erfani et al. [2015] studied the effects of Consciousness Raising tasks [CR tasks] and SBPTs on reading comprehension. Seventy midintermediate EFL students were offered to participate in. A proficiency test was used to homogenize the participants, followed by a questionnaire-based survey to see students' attitudes towards reading and focused tasks. Then, Group 1 [SBPTs] dealt with story completion and information exchanging. Group 2 [CR tasks] was involved in story completion including explicit instruction of rules and talking meaningfully one linguistic feature within a provided text by using their own linguistic resource. Specifically, group 1 was not instructed to use any grammatical structures but was reinforced their reading and question responding based on their existing knowledge. The instructor played the role of a facilitator to guide students to correct their mistakes and their friends' mistakes in groups. On the other hand, group 2 was expected to use explicit taught rule until they could use it in their own production. 
Before starting to read, the teacher would provide explicit explanation on grammar or vocabulary if students asked. After 10 weeks of treatment, a post-test and the same questionnaire were administered again to investigate students' attitudes towards the treatment. The results interpreted that the SBPTs were more effective than CR tasks. Indeed, the SBPTs had more positive effects on learners' attitudes in comparison with CR tasks.

Briefly, those mentioned studies have demonstrated students' attitudes towards focused tasks and Task-based approach. The majority of them express interests in the new method as it creates more opportunities to engage in communication [Rashtchi, 2012; Erfani et al., 2015]. Nevertheless, some students are hesitant about the new method as they commonly follow the traditional method.

There are numerous studies in relation to focused tasks. Prior studies can be summarized on the basis of strengths and weaknesses. Studies have yielded the impact and the effectiveness of focused tasks on grammar teaching. First, TBLT can help learners build up confidence and motivation for further learning. Particularly, it helps learners have motivation towards learning reading [Gana et al., 2013; Sheikh et al., 2016]. Second, learners have opportunities to engage in activities which may promote communication. It is recognized that teachers and students show positive attitudes towards TBLT since they are involved in a variety of communication activities [Raschtchi, 2012]. Also, learners have a chance of producing target language through production activities [Miri, 2015]. Third, students' previous knowledge can be activated through activities. As they are involved in activities in the beginning [i.e., contextualized information], they have to refer to preceding knowledge [Gana et al., 2013].

In spite of considerable strong points withdrawn from previous studies, there are still some inadequacies. First, lacking explicit instruction may have impacted upon students' learning. Specifically, dictogloss and film recalled tasks do not draw adequate learners' attention to form although they are both focused tasks [Patanasorn, 2012]. The findings of Raschtchi [2012] also shows that focus on form and explicit instruction are necessary for learning. Since students make mistakes, they expect to receive teacher's explanations in order to better their subsequent performance. Second, inadequate reproduction of target structures may make learners difficult to master certain grammatical features. In fact, the matching task may not be effective since it does not require learners to construct new sentences [Patanasorn, 2012]. Instead, the Reproduction activities may create opportunities for learners to produce target structure in a free manner. Third, most of the studies overlook at teaching reading using focused and unfocused tasks [Ahour et al., 2015; Sheikh et al., 2016], teaching reading using SBPTs and CR tasks [Erfarni et al., 2015] or teaching grammar using other grammatical aspects [e.g., Relative Clause, vocabulary, and so on ...]. No attention has been paid to teaching grammar with regard to comparing the alternative model [Task-based approach] and the PPP model using the English tenses as the instructional content.

From the previous studies, most researchers have reached a consensus that focused tasks with the employment of TBLT are effective in teaching grammar. Because of this, the current study endeavors to analyze deeply by providing a conceptual framework. As noted, it attempts to compare the effectiveness of the alternative model [Task-based approach] and the PPP model. In this study, the alternative model [adapted from Ellis, 2003, p. 244], which includes three main stages: pre-task, during task, and post-task, are fluency focused [Ellis, 2005, p. 6]. Meanwhile, the PPP model [adapted from Thornburry, 2008, p. 128], which comprises of three main stages: presentation, practice, production, is accuracy focused [Ellis, 2005, p. 4]. Noticing which is proposed by Schmidt [1990, 1994, 2001] is also taken into consideration to measure learners' grammatical performance. While the alternative model moves from implicit to 
explicit noticing, the PPP model moves from explicit and implicit noticing. Grammatical performance, furthermore, which is used to measure learners' grammatical explicit and implicit knowledge, is in form of the Discrete-point item test and the Integrative item test [Heaton, 1988 \& Brown, 2003]. In summary, the SBPTs are operationalized through the application of the alternative model. Based on the grounded theory and the conceptual framework, the present study strictly follows these procedures in order to have the research aims fulfilled satisfactorily

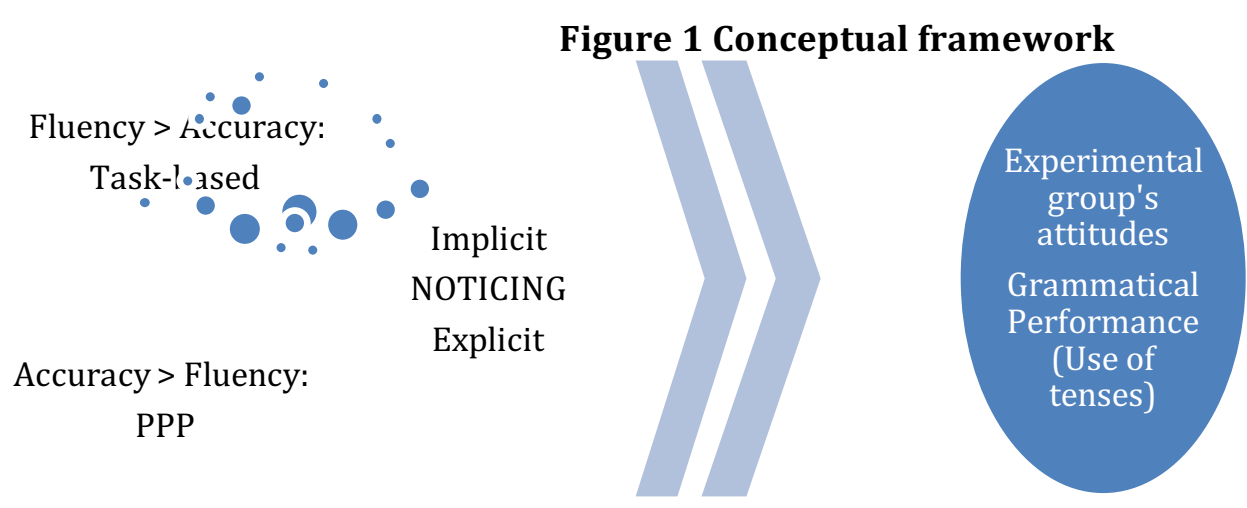

\section{Research questions [RQ]}

RQ1: What are the differences in the mastery of the English tenses between the group that received the Structure-Based Production Tasks and the group that received that PPP instruction?

RQ2: What kinds of effects does the treatment have on the experimental group's attitudes?

\section{Research design}

\section{METHODOLOGY}

The research adopted a non-equivalent Pre-Posttest Quasi-experimental design. The benefit of this approach is that "This design is very prevalent and useful in education since it is often impossible to randomly assign subjects" [McMillan and Schumacher, 2001, p. 342].

\section{Sampling}

To provide a way of characterizing the samples, convenience sampling was used. Although non-probability sampling appears not to be a representative of the whole population, it is the most common type of sampling in educational research [McMillan and Schumacher, 2001]. Also, Frankael et al. [2011, p. 100] hints that in case it is difficult to select a random or systematic non-random sample, the researcher can use convenience sampling carefully included information on demographic and sample characteristics. In this study, convenience sampling was recruited because this was the only selection that the researcher had.

\section{Participants}

Fifty nine participants who were in the intermediate level were offered to participate in. The cohorts were from many parts of Vietnam and had various backgrounds of English, so their knowledge of English was different. Each class had an average level of English. They were neither good at nor majored in English and were divided into two groups based on their final test performance.

\section{Data types \\ Proficiency test}

In this study, the Oxford Placement Test 1 [Allen, 2004] was implemented to check proficiency levels of the participants. In addition, the researcher would like to ensure whether proficiency 
levels would affect learners' performance. There were two parts in this test: listening and reading. This study focused on the SBPTs with the aim to teach grammar, so only reading section was used. The reading test comprised of 100 multiple choice items. This was a multiple-choice test for students to choose one correct answer from three answers within sixty minutes of completion.

\section{Pre-test and Post-test}

The pre-test and post-test were synthesized and compiled based on the interview with participants on their regular access to grammar books. Each test included 80 items divided into two parts: [1] Discrete-point item test [e.g., Multiple-choice test, 50 items] and [2] Integrative item test [e.g., Reproduction test, 30 items]. Duration for test completion was forty five minutes. The questionnaire was designed on the basis of the interview with participants in the experimental group. There were four main questions which focused on confidence, affection, anxiety and general evaluation.

\section{Procedures}

\section{Pre-stage}

A proficiency test was distributed to check proficiency levels of the participants [March $16^{\text {th }}$, 2015]. In a follow-up stage, a pre-test was offered to the cohorts [March 18 $\left.{ }^{\text {th }}, 2015\right]$. Next, the trial teaching practice was carried out with the experimental group. The researcher spent six periods trialing the new teaching method [March 23 ${ }^{\text {rd }}, 2015$ and March 25 th, 2015$]$. After that, she interviewed two students to get their feedback on the new treatment. She asked them about the content of the lesson and their opinion on the treatment. Basing on their feedback, the researcher could have specific information to adjust the lesson plans if needed.

\section{Implementation stage}

The experimental group first worked on listening or reading tasks with respect to the target grammatical structure without being told what the structures were. Then, they were presumably required to perform an oral task within time constraint which stimulated them to use the target feature. During this time, the researcher went around the class, observed, listened to students' talks and took notes of their mistakes. Following this, learners were invited to share their ideas with their friends. After that, they were required to work on controlled practice activities. On the ground of learners' sharing and mistakes, the target features and their mistakes were written on the board and directly elicited. That is to say, the teacher raised directly learners' consciousness to check meaning, form, and use of the target structure.

On the other hand, the control group continued learning with the traditional method. First, the participants were directly raised consciousness of the target grammatical structure through listening or reading tasks. Then, they worked on controlled practice activities followed by a free-er practice activity. Finally, they were required to perform a free oral task using the structure introduced previously.

In brief, the treatment [Task-based approach] of experimental group was different from that [PPP] of the control group in the way of implementing. In the first step, while the experimental group dealt with task framing, the control group was directly raised consciousness. In the second step, the experimental group performed a free oral task within time constraint whereas the control group worked on controlled practice activities such as filling in a blank, making a choice from supplied items and dealt with a free-er practice activity. In the third step, the experimental group was directly raised consciousness of their mistakes while the control group did a free practice activity using the structure they have just learned. 


\section{Post-stage}

A post-test was given to both groups in the last week of the experiment. The scores of these two tests were computed based on the Statistical Package for the Social Science [SPSS] of version 22 for Windows. The T-Test was used to compare the performance of the experimental group and the control group. In addition, the questionnaire was administered to the experimental group to explore their confidence, affection, anxiety and their general evaluation towards the treatment. The Pearson correlation was also computed to test whether there was a close relationship between students' confidence and anxiety.

\section{RESULTS}

In order to search for the answers, SPSS program 22 for Windows was used to calculate and interpret the statistics. To answer the research question 1, the Independent Sample T-Test was administered to find out the differences between two groups before and after the treatment. Besides, Paired Sample T-Test was used to analyze the discrepancies between the Integrative item pre-test and post-test of the experimental group. To answer the research question 2, the descriptive statistics and simple frequencies were employed. Also, One Sample T-Test was used to test whether the average mean of all questionnaire items was different from the hypothesized mean. The Pearson product moment correlation coefficient was used to determine the relationship between student's confidence and anxiety. The alpha set used to assert the significant difference between the mean scores of two groups in this study was $\mathrm{p}<$ 0.05 .

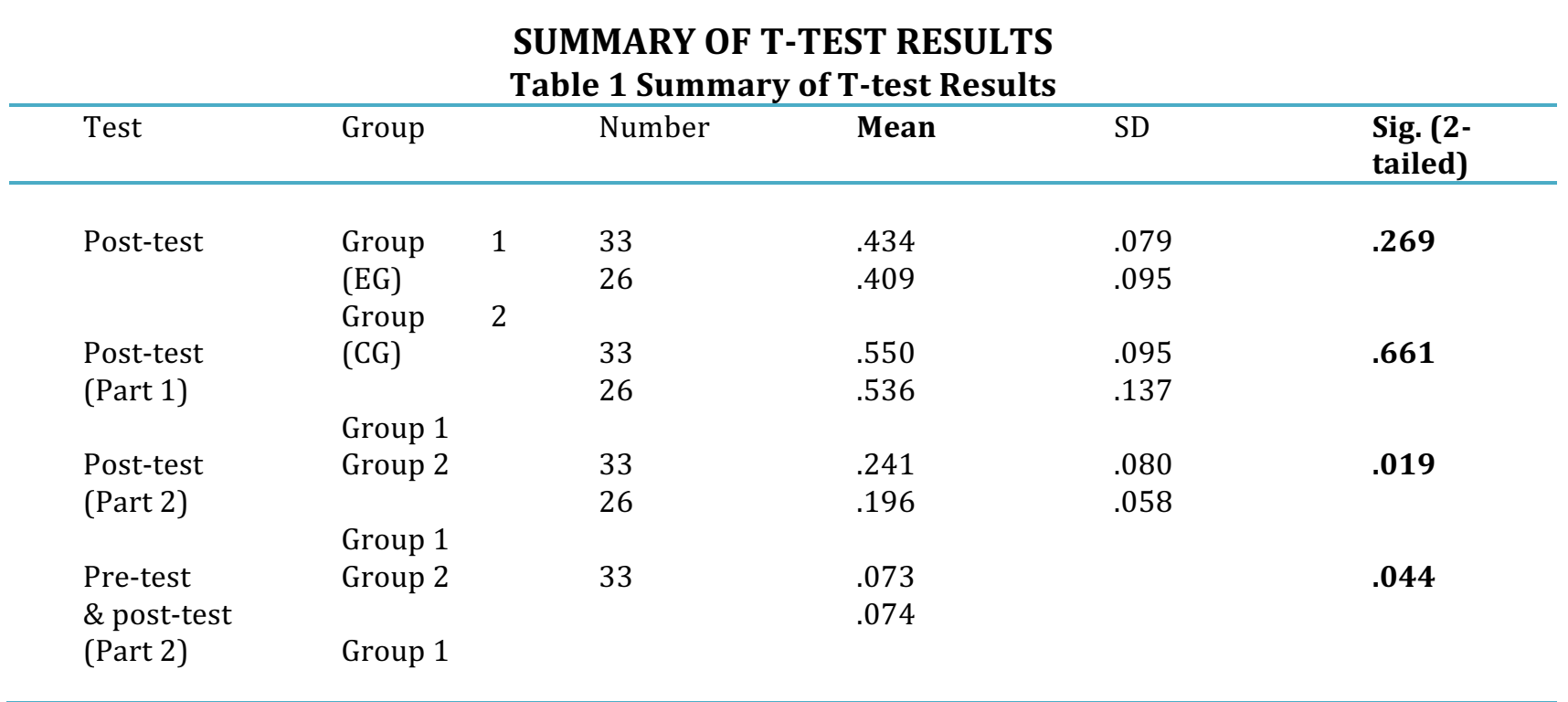

Inspection of the post-test mean in Table 1 indicated that Group 1[Experimental group] did not surpass Group 2 [Control group]. The mean of .434 and .409 produced probability level of .269, [>.05]. Therefore, it could be acknowledged that these results were insignificant.

It was apparent that the Group 1 did not differ from Group 2 in the Discrete-point post-test [i.e., the multiple choice test]. The discrepancy between two groups was so small, so the Sig. [2tailed] was quite high, at .661. Unexpectedly, no significant difference between two groups was evident.

Intriguingly, despite insignificant statistics, the Integrative item post-test [i.e., the Reproduction test] represented a significant difference. The mean of Group 1 was .241, higher than that of Group 2 which was at .196. This resulted in a significant value of .019, less than the 
alpha set value .05, which revealed that the experimental group showed a substantial improvement after the experiment.

When comparing the results of the Integrative pre-test and post-test in the experimental group, it was clear that statistical difference between the pre-stage and post-stage was found. The mean of .73 and .74 led to the Sig. [2-tailed] of .044 [<.05]. Obviously, statistically significant difference was detected.

\section{Attitudes towards the treatment}

The questionnaire focused on confidence, affection, anxiety, and general evaluation with five scales [i.e., totally not true to me, not true to me, partly true to me, true to me and totally true to me]. Before analyzing the data, the researcher recoded the scale of the questionnaire in question 3 [anxiety] in order to make the meaning logical. Participants' general attitude mean $[\mathrm{M}=3.46, \mathrm{SD}=.28]$ represented that students showed positive attitudes towards the treatment. Indeed, 32 [97.0\%] students had positive attitudes towards the SBPTs in comparison with 1 [3.0\%] students who had negative ideas. The respondents felt more confident of using the English tenses with a mean of 3.41 [SD=.45] and a mean of 3.33 [SD=.51] of anxiety, which resulted in significant correlation coefficient $r=.414$ [p =.017]. The affective factors also showed a mean of 3.64 [SD=.47], which also supported for this idea. Furthermore, when learners were asked about preference for the new method [Q4a], a relatively high mean of 4.03 $[\mathrm{SD}=.810]$ was revealed. These responses reflected that the participants were interested in the new treatment.

\section{Correlation results for the Experimental group}

There was a high negative correlation between confidence and anxiety in the experimental learners (Table 2). The results show correlation coefficient .414 and significance value at.017, which was lower than that of the standard value $[\mathrm{p}=0.05]$. Thus, it is apparent that there was a close connection between confidence and anxiety about using the English tenses.

Table 2 Correlation results between confidence and anxiety about using the English Tenses

\begin{tabular}{|l|l|r|r|}
\hline \multicolumn{2}{|c|}{ Correlations } & Confidence & $\begin{array}{c}\text { Anxiety } \\
\text { recoded }\end{array}$ \\
\hline Confidence & Pearson Correlation & 1 & $.414^{*}$ \\
& Sig (2-tailed) & & .017 \\
& $\mathrm{~N}$ & 33 & 33 \\
\hline Anxiety & Pearson Correlation & $.414^{*}$ & 1 \\
recoded & Sig (2-tailed) & .017 & 33 \\
& $\mathrm{~N}$ & 33 & \\
\hline
\end{tabular}

\section{Discussion}

\section{DISCUSSION AND CONCLUSION}

Although a number of research have revealed the effects of SBPTs, no research has mentioned the effects of SBPTs in the context of comparing with the traditional method. Consequently, the researcher would like to point out some explanations for the major findings of the study, which are organized on the basis of themes as follows.

\section{Why was the experimental group mean score higher though not significant difference from that of the control group?}

First, according to personal observation, learners have been deeply influenced by the ruledriven method in which target features are presented prior to communication. The study of Bagheri and Mahmoudi [2015] on learning grammatical cohesive devices corroborates this 
finding. Bagheri and Mahmoudi's impressive research proved that the participants favored traditional approach with an emphasis on explicit instruction compared to implicit instruction and incidental learning. In this study, the fact that the post-test mean [M=.434, $\mathrm{p}=.269]$ of the experimental group was just a little higher than that $[\mathrm{M}=.409, \mathrm{p}=.280]$ of the control group indicated that the traditional method had a profound impact on learners.

Second, it is probably because incidental learning has become a contributing factor to learners' memories. The results were in agreement with the ground-breaking study obtained by Sonbul and Schmitt [2010], which investigated L2 vocabulary acquisition. In their study, the experimental group was uninstructed and learned incidentally while the control group was given instruction. Their findings revealed that incidental learning might reflect lexical gains but it was modest. In the current study, specifically, when being asked about remembering grammatical points after the treatment 9 , a mean of 4.00 [SD $=.829$ ] was found. This suggests that incidental learning may help the experimental group improve learning. As Ellis [2003, p. 55] points out that "when performing Structure-Based Communicative Tasks, learners treat them as opportunities for communicating rather than for learning". Thus, any learning as a result of the Structure-Based Communicative Tasks is likely to be incidental.

Third, the result may be explained by that fact that perceptual salience with respect to the prominence of a form in the input is not adequate. As Skehan [1998, p. 49] concedes that if forms call learners' attention and are perceptually salient, they have a greater chance of impinging on consciousness. In this study, a relatively high mean $[\mathrm{M}=4.45, \mathrm{SD}=.564]$ of high frequency of structure representations demonstrates that target features in the input are frequent but perhaps salience is not adequate to catch learners' attention to target structures. Indeed, "Second language learners notice a language construction if they come across it often enough or if it stands out in some way" [Harmer, 2010, p. 44].

Fourth, a possible explanation for these results may be the lack of guided instruction. Guided instruction, according to Harmer [2010, p. 43], occurs when the teacher provides feedback on the task students have just been engaged in and is used to help students' explicit knowledge of some features. Indeed, the mean $[\mathrm{M}=2.55, \mathrm{SD}=1.148]$ of needs-based rule explanations implies that students are only raised consciousness of what they do not understand. In brief, guided instruction may play an important role in enhancing learners to notice target features as Harmer [2010, p. 44] elicits that learners may come across a language instruction through guided instruction if the teacher draws their attention to it.

Fifth, it seems possible that the results are due to inadequate cognitive comparison. As Thornburry [1997] shows that "noticing of the PPP model was customarily promoted through activities and procedures which involved input enhancement" [p. 326] while noticing of the alternative model related to corrective feedback. Indeed, when it comes to a correction, there is a mismatch between teacher's intention and students' outcomes. Schmidt \& Frota [1986] also affirm that "clarification requests made no impression whereas hearing the correct version immediately after making an error allowed him to match his present level with the target" [as cited in Thornburry, 1997]. The fact that there were no hindrances to raising problems with a mean of 4.27 [SD=.674] and students are free to use their language with a mean of 3.97 $[S D=1.053]$ in the questionnaire showed that learners did not adequately compare what they noticed in the input and their current output.

Sixth, insignificant differences can be explained in part by the proximity of focusing on form and communication. In fact, "it is difficult to bring about a focus on a specific linguistic feature while at the same time maintaining true communicativeness" [Ellis, 1997a, p. 216]. As learners 
know that the task is to provide them with a linguistic feature, they stop treating it as an opportunity to communicate and switch to learn. When being asked whether students had more productive performance through SBPTs, they partly showed an agreement with a mean of $3.15[\mathrm{SD}=.870]$, which indicated that they could not only focus on communication since they had to deal with grammatical structures.

Seventh, the results are likely to be related to the fact that the Structure-Based Production Tasks are used as "an increasing in control over forms that have already been internalized" [Ellis, 1997a, p. 216]. Indeed, SBPTs provide a means for learners to increase their linguistic competence under real operating conditions. These tasks are more appropriate for reviewing learned knowledge rather than teaching new knowledge.

Eighth, limited processing capacity may cause problems for learners to attend simultaneously both meaning and form. As Ellis [2009] points out that learners' capacity to learn grammatical features incidentally may depend on whether they are able to "dual task" successfully" [pp. 266 $\&$ 267]. The results are consistent with Wong's [2001] findings. In Wong's thorough study, learners' attentional resources may be available for reading comprehension rather than listening comprehension because they may have the control over the input in reading compared to listening. In this study, attention to form may play the role of a "backup procedure" in case meaning cannot provide an adequate interpretation" [Ellis, 2009, p. 265]. Indeed, adequate attention to both form and meaning may help learners transfer knowledge from short term memory to long term memory because "attention is the neccesary and sufficient condition for long-term memory storage to occur" [Schmidt, 2001, as discussed in Robinson, 2001, p. 16].

Ninth, the outperformance of the experimental compared to the control group in the Integrative item post-test indicates that the experimental group gains enough implicit grammatical knowledge during their performance in the interactive tasks [Purpura, 2004]. As learners are required to listen to a passage and then answer comprehension questions without being told what the target structures are, they perform naturally and well.

Tenth, a possible explanation for this might be that the experimental group had opportunities to deal with authentic exposure, so they performed better than the control group in terms of the Integrative item post-test. As Scrivener [2005] hints that "an authentic text will often be more useful for drawing attention to a range of various language points in action rather than a single target point" [p. 282]. As a result, the experimental group reproduced grammatical features better than the control group.

Last but not least, the fact that the experimental group exceeded the comparison group in terms of the Integrative item post-test suggested that long term storage has become the immediate resource for the experimental group as a result of implicit learning. Implicit learning, in this case, "can be viewed as incidental and involves some degree of attention to the input" [Ellis, 1997b, p. 118]. Put it another way, "the tasks do not make meaning primary or have much of a real-world relationship" [Skehan, 1998, p. 123]. The results corroborate the idea of Vosoughi and Mehdipour's [2013] influential study on the effects of Recognition Tasks and Production Tasks through incidental learning of Iranian EFL learners. In their study, the fact that the experimental group gained greater performance in Production tasks compared to the other indicated that incidental learning was more powerful when it was combined with the Production Tasks. In addition, better retention of lexical could be achieved through incidental learning. In this study, the Integrative item post-test mean [M=.241, $\mathrm{p}=.019]$ of the experimental group was higher than that $[\mathrm{M}=.196, \mathrm{p}=.015)]$ of the control group, which 
suggested that learners had retention of grammatical structures after learning with the treatment.

\section{Why did the experimental group perform better in the Integrative item test?}

First, automatic processing, which requires fast processing, may help learners focus on message rather than form as it is a necessary condition for long-term storage [Ellis, 2003,]. In this study, automatic processing may be a contributing factor to the performance of experimental group in the Integrative item test, which requires them to use the correct verb tense based on a hint supplied. Basing on the new target feature learners notice in the input, they may use it in their own production without conscious deliberation [Ellis, 1997a]. As noted in the Literature Review, this test reflects learners' implicit knowledge [Brown, 2003]. As a result, learners may activate their current resources to perform the task as Ellis [2003] states that "the role of the SBPTs in language teaching should be seen as that of automatizing existing knowledge" [p. 152].

Second, controlled processing, which is limited in capacity, requires conscious effort [Ellis, 2003]. In this research, controlled processing may be a contributing factor to the performance of the control group in the Discrete-point item test which asks learners to choose one correct answer from four answers. The fact that the experimental group did not surpass the control group in the Discrete-point item test suggested that the control group favored controlled processing which focused on linguistic form acquisition rather than the content of the message. As indicated in related Literature review, it reflects learner's explicit knowledge [Heaton, 1988 \& Brown, 2003].

Briefly, the statistic results obtained from the study answered the two main research questions. Specifically, the study showed that the experimental group did not perform better than the control group. Nevertheless, there was an improvement in the Integrative item test of the experimental group. In addition, the data gained from the questionnaire illustrated that students had favorable attitudes towards the treatment.

\section{IMPLICATIONS}

First, the SBPTs are what the academic managers need to endeavor if they would like to enhance students' grammatical achievement. As we are concerned, the traditional method has been widely applied and has some certain limitations in helping learner better grammar and communication. Thus, SBPTs may be a useful approach to help students gain and remember grammatical knowledge through communication within time constraint in class.

Second, the findings of the study suggest that teachers should give more heavy weight to the SBPTs while integrating with the rule-explanation method. Though traditional method is commonly used, it would be more convincing if teachers give students more opportunities to discuss target grammatical features so as to activate knowledge they have just known. Furthermore, teachers should conduct lessons with the SPBTs naturally. That is to say, teachers should guide learners to focus on both communication and target language. In addition, teachers should be flexible in teaching grammar using the SBPTs for students in intermediate and upper-intermediate levels. Instead of moving from language to communication, teachers may change direction from communication to language.

Third, the evidence from this study suggest that further research regarding the application of the SBPTs should be addressed with a variety of aspects in language teaching so as to have a wider perspective. In this study, the SBPTs show effectiveness in grammar teaching, particularly with the English tenses. 


\section{ACKNOWLEDGMENTS}

The author would like to express her gratitude and appreciation to those who have advised, supported and contributed to the completion of the research project.

First of all, I would like to send my greatest gratitude to my supervisor, Dr. Nguyễn Thu Hương, for his valuable guidance, advice and encouragements. His kind support, explanations, and comments have encouraged me to complete the project. In addition, he supplied me with useful sources of materials in language teaching and in doing research. I owed him for his time helping me with statistical analyses of the data and discussing the results with me. Without his excellent academic guidance, my thesis would not have been possible.

Next, I am grateful to my friends and colleagues Ms. Đỗ Ngọc Anh and Ms. Trần Ngọc Quỳnh Như, Ms. Châu Thục Quyên for their enthusiastic contributions to proofreading my thesis, revising the English and Vietnamese versions of the questionnaire.

I also would like to acknowledge the Head of the Center, Dr. Ngô Thị Thanh Vân, who allowed me to conduct the study in Tôn Đức Thắng University. Without her assistance, my thesis would not have been completed.

I would like to thank all of my students who joined in the study for their valuable time, their great effort to complete a variety of tests and questionnaires. The thesis would not have been completed without their cooperation.

Finally, I would send my deepest gratitude to my parents who have provided me with a source of inspiration, motivation and encouragement for me to complete this research successfully

\section{References}

Ahour, T. \& Shemshadsara, Z. G. [2015]. The Impact of Focused and Unfocused Tasks on University Students' Grammatical Achievement. Theory and Practice in Language Studies, 5 [1], 124-133.

Allen, D. [2004]. Oxford Placement Test 1. Oxford: Oxford University Press.

Bachman, L. F. \& Pamler, A. S. [1996]. Language Testing in Practice: Designing and Developing Useful Language Tests. Oxford: Oxford University Press.

Badri, A., Nazari, J. \& Badri, A. (2015). The Effects of Input Enrichment (Focused-Task) on Students' Grammar Acquisition. International Journal of Educational Investigation, 2 (1), 1-9.

Bagheri, S. \& Sheikh, S. \& Aghajanzadeh, M. [2016]. The Effect of Using Focused Tasks through Input Flooding on Reading Comprehension Skill of Iranian High School Students. Modern Journal of Language Teaching Methods, 6 [1], 115-132.

Bagheri, Z. \& Mahmoudi, A. [2015]. Differential Effects of Explicit, Implicit and Incidental Teaching on Learning Grammatical Cohesive Devices. Theories and practice in language studies, 5 [11], 2348-2355.

Brown, D. H. [2003]. Language Assessment: Principles and Classrooms Practices. New York: Longman.

DeKeyser, R. [2007]. Practice in a Second Language. Cambridge: Cambridge University Press.

Ellis, R. [1997a]. SLA Research and Language Teaching. Oxford: Oxford University Press.

Ellis, R. [1997b]. Second Language Acquistion. Oxford: Oxford University Press.

Ellis, R. [2001]. Some Thoughts on Testing Grammar: an SLA Perspective. In Elder, C. \& Brown, A. \& Grove, E. \& Hill K. \& Iwashita, N. \& Lumley, T. \& McNamara, T. \& O'Loughlin, K. [Eds.], Experimenting with Uncertainty: Essays in Honour of Alan Davies [pp. 251-63]. Cambridge: Cambridge University Press.

Ellis, R. [2003]. Task Based Language Learning and Teaching. Oxford: Oxford University Press.

Ellis, R. \& Loewen, S. \& Elder, C. \& Erlam, S. \& Philp, J. \& Reinders, H. [2009]. Implicit and Explicit knowledge in Second Language Learning, Testing and Teaching. Bristol: Multilingual Matters. 
Erfani, S. S. \& Torkamani, A. [2015]. The Impact of Consciousness Raising vs. Structure Based Production Tasks on Reading Comprehension of Iranian Mid-Intermediate EFL Learners. Theory and Practice in Language Studies, 5 [5], 1078-1089.

Fraenkel, J. R. \& Wallen, N. E., \& Hyun, H. H. [2011]. How to Design and Evaluate Research in Education. New York: Mc Graw-Hill.

Gana Kumara, D., G., \& Padmadewi, N., N., \& Suarnajaya, I., W. [2013]. The Effect of Task-Based Language Teaching and English Grammar Mastery toward Reading Comprehension of the Second Semester Students. E-journal Program Pascasarjana Universitas Pendidikan Ganesha. Program Studi Pendidikan Bahasa Inggris, 1.

Harmer, J. [2010]. The Practice of English Language Teaching. Harlow: Pearson Longman.

Heaton, J. B. [1988]. Writing English Language Tests. New York: Longman.

Leow, R. P. [2007]. Input in the L2 classroom: An Attentional Perspective on Receptive Practice. In Dekeyser, R., M. [Ed.], Practice in a Second Language: Perspectives from Applied Linguistics and Cognitive Psychology [pp. 21-51]. Cambridge: Cambridge University Press.

Loschky, L. \& Bley-Vronman, R. [1990]. “Creating Sructure-Based Communication Tasks for Second Language Development”. University of Hawaii Working Papers in ESL, 9 [1], 161-212.

Loschky, L. \& Bley-Vronman, R. [1993]. Grammar and Task Based Methodology. In Crookes. G. and Gass, S. 1993 [Eds.], Tasks and Language Learning: Integrating Theory and Practice [pp. 123-168]. Clevedon: Multilingual Matters.

McMillan. J. H. \& Schumacher, S. [2001]. Research in Education: A Conceptual Introduction. New York: Priscilla McGeehon.

Miri, M. [2015]. The Impact of Different Types of Tasks [Structured and Unstructured)] on the Production of Relative Clauses and Lexical Diversity of Iranian EFL University Students. Theory and Practice in Language Studies, 5 [8], 1682-1687.

Patanasorn, C. [2012]. Comparing Focused Tasks on Eliciting Targeted LREs during Learner-Learner Interaction, Foreign Language and Language Teaching Journal, 1 [1], 70-90.

Purpura, J. E. [2004]. Assessing Grammar. Cambridge: Cambridge University Press.

Rashtchi, M. \& Keyvanfar, A. [2012]. Form-focused Instruction: A New Interpretation of TBLT in Iranian EFL Setting. Journal of Language Teaching and Research, 3 [1], 159-165.

Robinson, P. [2001]. Cognition and Second Language Instruction. Cambridge: Cambridge University Press.

Schmidt, R. \& Frota, S. [1986]. Developing basic conversational ability in a second language: a case study of an adult learner of Portuguese". In Day, R. R. [Ed.], Talking to Learn: Conversation in Second Language Acquisition [pp. 237-326]. Rowley, M.A: Newbury House.

Schmidt, R. [1990]. The Role of Consciousness in Second Language Learning. Applied Linguistics, 11 [2], $129-158$.

Schmidt, R. [2001]. Attention. In Robinson, P. E. [Ed.], Cognition and Second Language Instruction [pp.3-33]. Cambridge: Cambridge University Press.

Scrivener, J. [2005]. Learning Teaching: A Guide Book for English Language Teacher. Oxford: Macmillan.

Skehan, P. [1998]. A Cognitive Approach to Language Learning. Oxford: Oxford University Press.

Sonbul, S. \& Schmitt, N. [2010]. Direct Teaching of Vocabulary after Reading: is it worth the effort? English Language Teaching Journal, 64 [3], 253-259.

Thornburry, S. [2008]. How to Teach Grammar. Harlow: Pearson.

Thornburry, S. [1997]. Reformulation and Reconstruction: Tasks that Promote 'Noticing'. ELT Journal, 51 [4], $336-$ 335.

VanPatten, B. [1996]. Input Processing and Grammar Instruction in Second Language Acquisition. Norwood: Ablex.

Vosoughi, H. \& Mehdipour, Z. [2013]. Effects of Recognition Task and Production Task on Incidental Vocabulary Learning of Iranian EFL Learners. International Research Journal of Applied and Basic Sciences, 4 [2], $356-363$.

Wong, W. [2001]. Modality and Attention to Meaning and Form in the Input. Studies in Second Language Acquisition, 23 [3], 345-368. 